finishes with an exciting exposition of the techniques and the future possibilities of cloning experiments. The corresponding section in Orten and Neuhaus is rather less stimulating, and perhaps the fact that it is entitled "Genetic Control of Metabolism" is an important clue to the more metabolic and physiological emphasis of the book.

In both books each chapter is followed by an extensive and up-to-date list of reviews and monographs for further reading. These are better presented by Lehninger who categorizes the references rather than just presenting them as one long list. In addition, in Lehninger each chapter is also followed by sets of problems which are very imaginative - and the answers are given at the back of the book.

At first I was rather uncertain about Biochemistry Illustrated. After further deliberation I feel that this is an interesting and potentially valuable new venture. The book is unconventional in being, in essence, 200 or so pages of clear diagrams and schemes, each illustration being supported by a concise explanatory text of 5-10 lines. The fundamentals of mammalian metabolism and molecular genetics are covered. The authors' special interest in medical education emerges in places.
It will be interesting to see what niche this book eventually comes to occupy. The authors consider that it may serve to make non-specialists such as school teachers aware of the principal trends in biochemistry and that it may be of use to students in developing countries whose English may be limited. I also suggest that it may offer a suitable way of advertising the subject to students one wishes to entice into courses in biochemistry.

David Saggerson is Senior Lecturer and Tutor to Medical Students in the Department of Biochemistry, University College London.

\section{Facing the music of immunology}

John Humphrey

\section{Immunology: The Science of Self- \\ Nonself Discrimination. \\ By Jan Klein.}

Wiley: 1982. Pp.687. £62.10, \$93.10.

JAN KLEIN is a highly respected immunogeneticist. Many might have thought of him as an immunologist, but not so himself. In his preface he states

I have a confession to make: when I started to work on the book, I knew little immunology. I knew something about one branch - the one I am actively involved in - but next to nothing about the rest ..... Finally, I decided to do something about my appalling lack of knowledge; I decided to write a textbook of immunology. So, in contrast to most authors who undoubtedly write textbooks for the very noble goal of educating their students, I wrote this book for the very egotistical reason of educating myself.

The result is the most complete textbook of immunology comprised within one cover that I know. It has been compiled partly from the author's own knowledge, but mainly from a highly intelligent culling from up-to-date reviews and books on different aspects, larded with bits of history and with references to works of art which have struck Jan Klein as apposite, and which lighten the generally erudite exposition.

One admirable consequence of his approach has been that where the experiments from which the data were derived are complicated, and the explanations require clear thinking and clear exposition (both by the author and the reader), Jan Klein takes us with him through the whole argument. This involves setting out the underlying biological or biochemical mechanisms, describing the principles of the experiments, and using clear and often original diagrams to support the interpretations which are reached. He does not take it for granted, for example, that the reader will carry in his or her head the alphabetic notation for amino acids used in peptide se- quences, or the major histocompatibility determinants of different strains of mice and recombinants, but sets them out in tabular form. The book in fact contains many tables of relevant data (e.g. gene sequences, amino acid sequences, lists of macrophage products, lymphokines, HLA determinants, immunoglobulin allotypes, complement components) which would otherwise have to be sought in specialized books and articles.

The structure of the book is described as a symphony, with a first movement about history, a second about structure (of the animals, the organs, the receptors and the molecules involved), a third about mechanisms (macrophage, T-lymphocyte and B-lymphocyte dominated), the fourth being the synthesis (defence reactions in action). The movements are given greatly dif-

ferent weight, with the more recent exciting discoveries about the evolution and control of the immune response having priority. But practically all aspects of immunology come in, including - though relatively superficially - clinical conditions.

All of this is an astonishing feat, even though the 667 pages of text are printed in double columns. It is a book for advanced students and teachers, rather than beginners, and would need to be supplemented by a textbook about the clinical conditions which do not necessarily make immunological sense before it could be taken as a guide to practice. Nevertheless, even at its price, I regard it as a best buy.

John Humphrey is Emeritus Professor of Immunology at the Royal Postgraduate Medical School, University of London.

\section{Membranes-how they work, what they do}

\section{Michael Selwyn}

Membrane Biochemistry.

By E. Sim.

Chapman \& Hall/Methuen: 1982.

Pp.80. Pbk f2.95, \$6.50.

Dynamics of Biological Membranes:

Influence on Synthesis, Structure and Function.

By M.D. Houslay and K.K. Stanley. Wiley: 1982. Pp.330. Hbk f23, \$52.65; pbk £8.90, \$19.95.

Chloroplasts and Mitochondria, 2nd Edn.

By Michael Tribe and Peter Whittaker. Edward Arnold: 1982. Pp.84.

£3.10, \$8.95.

Mitochondria, Chloroplasts and Bacterial Membranes.

By J.N. Prebble.

Longman: 1981. Pp.377.

f12.95, $\$ 26$.

SEVERAL sub-cellular organelles, including mitochondria and chloroplasts, are fundamentally specialized membranes, and their activities cannot be understood without a thorough grounding in membrane biochemistry. It is this principle that links together the four books reviewed here, although they quite clearly split into two groups. Sim with Houslay and Stanley are concerned with the properties of membranes, while Prebble and Tribe and Whittaker write from the viewpoint of the activities of the organelles.

Sim's Membrane Biochemistry is an admirable little book which is very readable and informative about the lipid and protein components, structure, biosynthesis and assembly of biological membranes (membrane functions are the subject of another but unfortunately dated book in the same series). The material is of necessity presented in a concise form but full reference to reviews and to the original literature is provided. Very occasionally compression renders a passage potentially misleading but my major criticism is that some of the diagrams are very poor indeed (freeze-etching suffers in both respects). Overall the book is good reading for finalyear undergraduates and also provides their teachers, or research workers, including non-specialists, with an excellent up-to-date survey.

In Dynamics of Biological Membranes, Houslay and Stanley emphasize the roles of fluidity and motion in membrane processes, and their evident enthusiasm for their subject aided by the excellent photographs make a stimulating book. The 